\title{
ASSESSING THE PREVALENCE OF EARLY CHILDHOOD CARIES AND THE ASSOCIATED DETERMINANTS IN A GROUP OF PRESCHOOL CHILDREN: RESULTS FROM A NATIONAL ORAL HEALTH SURVEY IN EGYPT
}

\author{
Reham Abou El Fadl*, Mona Abdel Fattah** and Mona Ezz ${ }^{* *}$
}

\begin{abstract}
Objective: This study provides information on the prevalence of early childhood caries among a sample of Egyptian Preschool children and the potential determinants associated with this condition.

Methods: A total of 651 preschool children were randomly selected from 160 gathering points in 26 governorates in Egypt. A face to face interview was conducted with children's primary caregivers and data on socioeconomic status, oral hygiene practices and feeding habits was collected. Information on caries experience was also recorded through dental examination following a standardized clinical protocol based on World Health Organization measures.
\end{abstract}

Results: More than $67 \%$ of the examined children had at least one decayed primary tooth and the mean dmf score was 3.3. Girls had lower mean dmf scores in comparison to boys. A weak positive correlation was detected between $\mathrm{dmf}$ scores in children and maternal caries experience $(\mathrm{r}=0.130, \mathrm{P}<0.001)$ whereas the coorelation with frequency of tooth brushing was weak negative $(\mathrm{r}=-0.093, \mathrm{p}<0.001)$.

Conclusions: Dental treatment needs among Egyptian preschool children are quite high and thus urging actions towards promoting oral health status of this population group need to be undertaken at community levels.

KEY WORDS: Early childhood caries, risk factors, preschool children, Egypt .

\section{INTRODUCTION}

Though dental caries is a preventable disease at both individual and community level ${ }^{[1,2]}$ and despite the steady decline in its incidence in some developed countries yet it is still considered one of the most prevalent chronic conditions worldwide. ${ }^{[3]}$

\footnotetext{
* Lecturer, Pediatric Dentistry and Dental Public Health, Faculty of Dentistry , Ain Shams university, Cairo, Egypt, MPH, Imperial College London.

** Dental Department Ministry of Health and Population, Cairo, Egypt.
} 
Early childhood caries (ECC), a common form of tooth decay which affects children 71 months of age or younger, ${ }^{[4]}$ poses a serious public health issue especially in deprived and socially disadvantaged populations where the majority of decayed teeth are left untreated.

The pattern of ECC reflects a specific risk profile related to socio demographic, cultural and lifestyle factors. Low income families, malnourishment, low levels of maternal education, for example, have been strongly linked to less positive oral health behaviors, less utilization of dental services and in turn high prevalence of ECC. ${ }^{[5]}$ Being associated with eating and sleeping disturbances, and because in its advanced stages it might cause pain and dental abscesses, ECC negatively affects children's quality of life. ${ }^{[6-9]}$ Moreover, the condition can adversely affect growth patterns, speech development and increase a child's risk to develop dental caries in the permanent dentition. ${ }^{[10]}$

According to the 2015 Global burden disease study, globally, at least 560 million children have caries in their primary dentition. ${ }^{[3]}$ In the Middle East, based on the findings of various epidemiological studies in some countries such as Saudi Arabia, United Arab Emirates, Kuwait and Qatar the prevalence of ECC was found to be high. [11-15] In Egypt, however, because epidemiological data on prevalence of various oral diseases was quite scarce, in 2013-2014 a national oral health survey was conducted and is considered the first population-based dental survey at country level in the last two decades. ${ }^{[16]}$

The aim of the current study was to provide information on the prevalence of ECC in a sample of Egyptian preschool children and some of the key maternal and child factors associated with the development of this condition.

\section{SUBJECTS AND METHODS}

\section{Study design/ethical considerations}

This cross-sectional study is a part of a national oral health survey which was conducted in Egypt in the year 2013-2014 by the Dental department, Ministry of Health and population under the auspices of the Country office of the World Health Organization(WHO). ${ }^{[16]}$ The study proposal was revised and approved by the Research Ethic Committee - Egyptian Ministry of Health and Population on $7^{\text {th }}$ May 2013 and the survey was conducted over a period of 9 months from September 2013 to May 2014. The study investigators explained to all participants the purpose of the survey; the benefits for the Egyptian population; privacy protection; and their right to refuse to participate or withdraw at any point while conducting the survey. The caregivers of all examined children had to provide a signed informed consent form in Arabic language prior to children's enrollment in the study.

\section{Sampling}

Generally, in the national survey, a "MultiStage Stratified Cluster" Sampling technique was used as shown in Table (1). A total of 651 children were randomly selected from 160 gathering points located in 26 governorates in Egypt. The gathering points were mainly in mother and child primary healthcare centers however, in some governorates, some participants were recruited from households, public hospitals and sport clubs. This was done with the assistance of Central Administration of Dentistry and Heads of Dental Departments in each governorate.

\section{Inclusion/Exclusion criteria}

Only preschool children with age range from 3 to 6 years whose parents signed an informed consent were included. Any children who participated in the national survey and had any erupting permanent teeth were excluded from the statistical analysis of this study. 


\section{Study Procedures}

\section{Questionnaire}

A face to face interview was performed and the primary caregiver of each child participant (i.e. the person with the day to day responsibility for the care of the child) answered the study questionnaire on behalf of the child. Demographic data was collected as regards to place of residence (urban or rural), number of siblings, parents' level of education. The questionnaire measured other risk and protective factors for dental caries such as maternal caries experience, oral hygiene practices and dietary habits among children.

\section{Clinical examination}

Caries experience was measured according to WHO standards using the $\mathrm{dmft}$ index which is based on presence of cavitated lesions in primary teeth such that the maximum dmft score (decayed/ missing/filled teeth) per child could be 20. [17] Dental examiners followed a standardized protocol to record information about caries experience of all participants and the study clinical protocol was designed to collect tooth-specific caries data rather than surface-level measures. Examinations were conducted in a dental office or in the field. The examination for dental caries was conducted with a plane mouth mirror and proceeded in an orderly manner from one tooth or tooth space to the adjacent tooth or tooth space. Usually subjects were examined seated in a chair with a high backrest with the examiner standing behind or in front of the chair. Investigators used lightweight battery-operated portable light sources and subjects faced away from any natural light source to avoid variation in illumination. Only cotton rolls and gauze were used to dry the teeth.

All examiners followed strict infection control guidelines such that disposable masks and gloves were used throughout the whole procedures of the survey. All instruments were individually bagged and sterilized and surfaces that were touched by the examiners were covered by impermeable plastic barriers.

\section{Statistical analysis}

Categorical variables were presented in frequency tables (number $\&$ percent) while continuous variables such as age were provided as descriptive statistics (mean, standard deviation, standard error, median, minimum and maximum). Chi-square test or its subsidiaries were used to calculate the $\mathrm{p}$ value for categorical variables and t-test or ANOVA were used to calculate the $p$ value for continuous variables. Spearman's Correlation Coefficient " $r$ " was used to measure the direction and strength of correlation between variables.

TABLE (1) Multi stage Stratified Sampling technique

\begin{tabular}{|l|l|l|}
\hline \multicolumn{1}{|c|}{ Sample Stage } & \multicolumn{1}{|c|}{ Unit } & \multicolumn{1}{c|}{ Comments } \\
\hline Strata: & Provinces & 4 provinces \\
\hline Primary Sampling Unit (PSU): & Governorates & 27 governorates \\
\hline Secondary Sampling Unit (SSU): & Civilization (Rural \& Urban) & $\begin{array}{l}\text { Cairo, Alexandria, Suez, Port Said } \\
\text { and Luxor have no rural areas }\end{array}$ \\
\hline Elementary Unit (EU): & $\begin{array}{l}\text { Mother and child health care centers, public } \\
\text { hospitals, work places, schools, sports clubs, } \\
\text { orphanages, households. }\end{array}$ & 160 elementary units \\
\hline Final Unit (FU): & Persons & Total number of persons, $=10144$ \\
\hline
\end{tabular}




\section{RESULTS}

In Egypt's national oral health survey, a total of 651 preschool children were examined. The numbers of girls and boys were almost equally distributed in the study, $50.5 \%$ and $49.5 \%$ respectively, which is close to official census (males: females: $51 \%$ : $49 \%$ ). $67.7 \%$ of examined children had at least one decayed tooth in their primary dentition (Figure 1) whereas $11.6 \%$ had missing tooth/teeth. The mean $\mathrm{dmft}$ index score in the overall sample was 3.3, such that the mean $\mathrm{d}, \mathrm{m} \& \mathrm{f}$ scores were 3.1,0.2 and 0.1 respectively i.e. $94 \%$ of this index was related to its d-component, while the $\mathrm{m}$ - and f-components were 4 and $2 \%$, respectively. (Figure 2)

Geographically, Egypt is divided into 27 governorates five of which are fully "urban" (Cairo,
Alexandria, Suez, Port Said and Luxor) whereas all other governortes have a mixture of "urban" and "rural " settings such that 9 governorates comprise Lower Egypt in the Nile Delta region, eight lie in Upper Egypt along the Nile river South and five frontier governorates cover Sinai and the deserts which lie in the West. According to the survey findings, it was found that children living in rural areas were at higher risk to develop ECC when compared to those in urban regions. In addition, boys tend to have higher mean dmf scores than girls. (Table 2)

Regarding factors associated with development of ECC, a weak negative correlation was detected between frequency of teeth brushing and $\mathrm{dmf}$ mean values $(r=-0.093, p<0.001)$ as shown in figure 3 .

TABLE (2) Variations in dmft mean values based on gender and place of residence

\begin{tabular}{|c|c|c|c|c|c|c|c|c|c|c|}
\hline & \multicolumn{2}{|c|}{ Lower Egypt } & \multicolumn{2}{|c|}{ Upper Egypt } & \multicolumn{2}{|c|}{ Civilized } & \multicolumn{2}{|c|}{ Desert/ Frontier } & \multicolumn{2}{|c|}{ Total } \\
\hline & Mean \pm SD & $\begin{array}{l}\text { Min- } \\
\text { Max }\end{array}$ & $\begin{array}{c}\text { Mean } \pm \\
\text { SD }\end{array}$ & $\begin{array}{l}\text { Min- } \\
\text { Max }\end{array}$ & $\begin{array}{c}\text { Mean } \pm \\
\text { SD }\end{array}$ & $\begin{array}{l}\text { Min- } \\
\text { Max }\end{array}$ & $\begin{array}{c}\text { Mean } \pm \\
\text { SD }\end{array}$ & $\begin{array}{l}\text { Min- } \\
\text { Max }\end{array}$ & $\begin{array}{c}\text { Mean } \pm \\
\text { SD }\end{array}$ & Min-Max \\
\hline Male & $4.1 \pm 3.9$ & $0-19$ & $3.2 \pm 3.4$ & $0-18$ & $2.6 \pm 3.3$ & $0-18$ & $3.2 \pm 3.6$ & $0-17$ & $3.5 \pm 3.7$ & $0-19$ \\
\hline Female & $3.5 \pm 3.7$ & $0-19$ & $3.2 \pm 3.4$ & $0-16$ & $2.6 \pm 3$ & $0-20$ & $3.6 \pm 3.3$ & $0-10$ & $3.2 \pm 3.5$ & $0-20$ \\
\hline Rural & $3.9 \pm 3.8$ & $0-19$ & $3.3 \pm 3.4$ & $0-18$ & - & - & $3.4 \pm 2.6$ & $0-8$ & $3.7 \pm 3.4$ & $0-20$ \\
\hline Urban & $3.5 \pm 3.8$ & $0-18$ & $2.9 \pm 3.4$ & $0-18$ & $2.6 \pm 3.1$ & $0-20$ & $3.3 \pm 3.5$ & $0-17$ & $3.3 \pm 3.6$ & $0-20$ \\
\hline Total & $3.8 \pm 3.9$ & $0-19$ & $3.4 \pm 3.5$ & $0-15$ & $3 \pm 3.3$ & $0-20$ & $3.3 \pm 3.5$ & $0-17$ & $3.5 \pm 3.6$ & $0-20$ \\
\hline
\end{tabular}

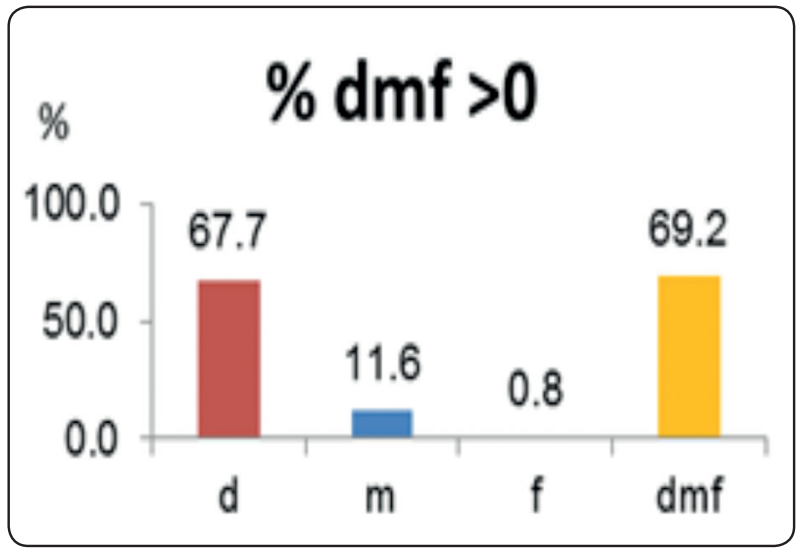

Fig. (1) Percentage of Preschool children with dmf score $>0$

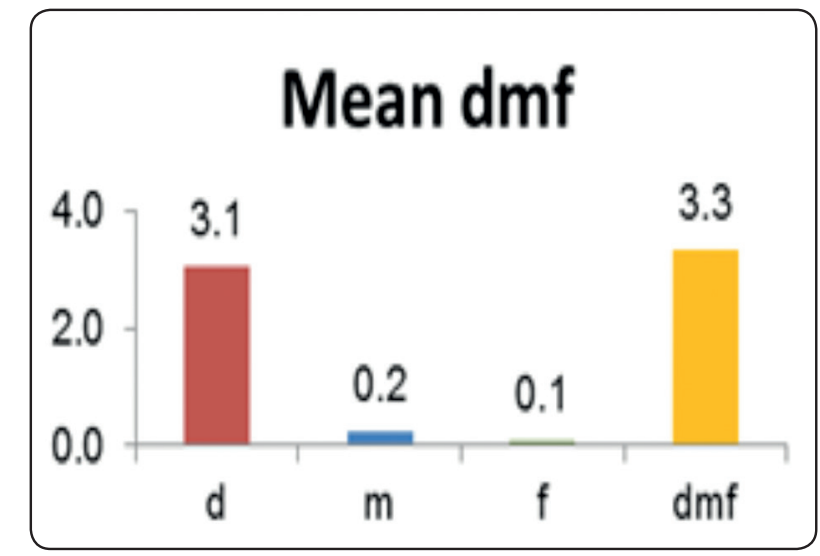

Fig. (2) Mean values of "d", "m", and "f" scores, and mean dmf score 


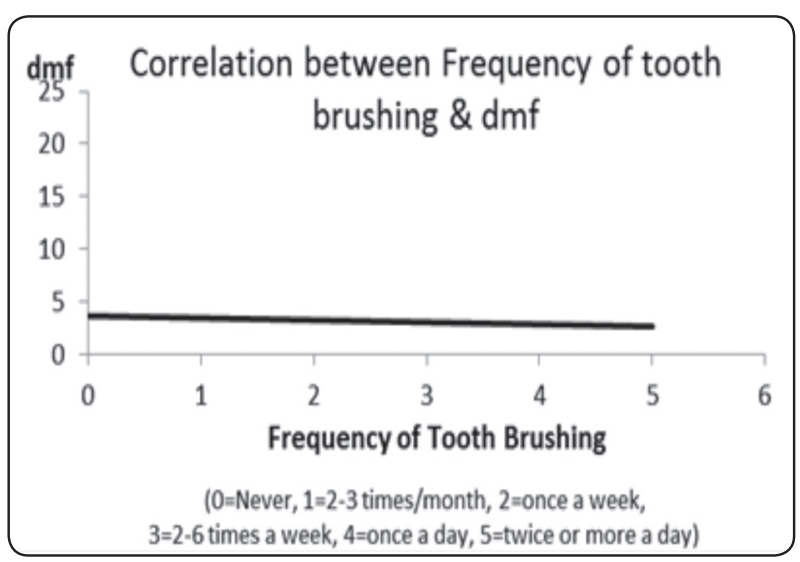

Fig. (3) Correlation between frequency of tooth brushing and dmf scores

TABLE (3) Relationship between food consumption and dmf scores

\begin{tabular}{|c|c|c|c|}
\hline & \multicolumn{3}{|c|}{$\mathrm{dmf}$} \\
\hline & Spearman's r & Correlation & $\begin{array}{c}\text { Sig. } \\
\text { (2-tailed) } \\
(\mathrm{p}<0.05)\end{array}$ \\
\hline Fresh fruits & 0.053 & zero & 0.010 \\
\hline $\begin{array}{l}\text { Biscuits \& } \\
\text { Cake }\end{array}$ & $0.101 *$ & $\begin{array}{c}\text { weak } \\
\text { positive }\end{array}$ & 0.000 \\
\hline Jam or Honey & 0.014 & zero & 0.494 \\
\hline $\begin{array}{l}\text { Chewing gum } \\
\text { with sugar }\end{array}$ & $0.111 *$ & $\begin{array}{l}\text { Modest } \\
\text { positive }\end{array}$ & 0.000 \\
\hline $\begin{array}{l}\text { Fizzy drinks or } \\
\text { Bottled Juices }\end{array}$ & 0.041 & zero & 0.043 \\
\hline Halawa & -0.005 & zero & 0.809 \\
\hline $\begin{array}{l}\text { Sugar in hot } \\
\text { drinks }\end{array}$ & 0.033 & zero & 0.109 \\
\hline
\end{tabular}

*Significant correlation p value $<0.001$

As shown in Table 3, the association between eating certain sugary food items such as biscuits, cake and chewing gum with sugar was weak positive ( $\mathrm{r}=0.101, \mathrm{r}=0.111$ respectively). Within the sample of preschool children included in this survey, whereas the association between severity of ECC and level of maternal education was insignificant, (Fig. 4) there was weak positive correlation between Mother /siblings caries experience and $\mathrm{dmf}$ scores $(\mathrm{r}=0.130, \mathrm{p}<0.001)$. (Fig. 5)

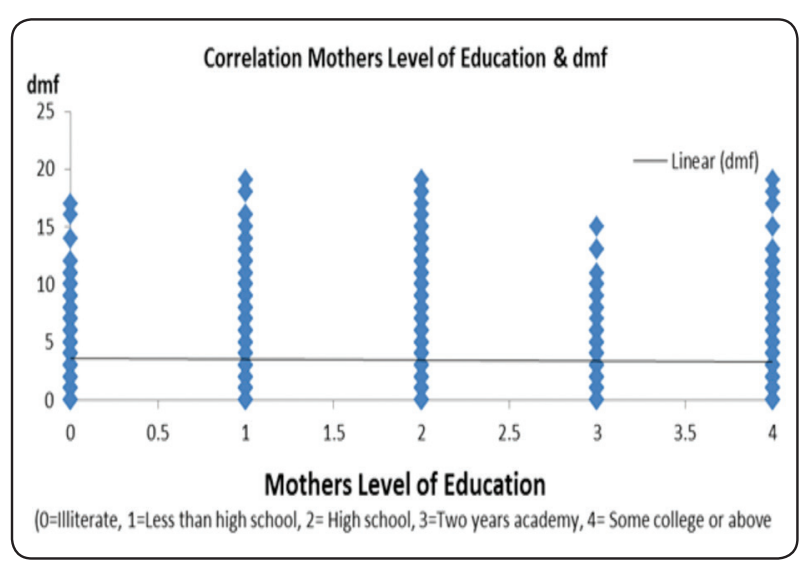

Fig. (4) Correlation between Mother's level of education and dmf scores

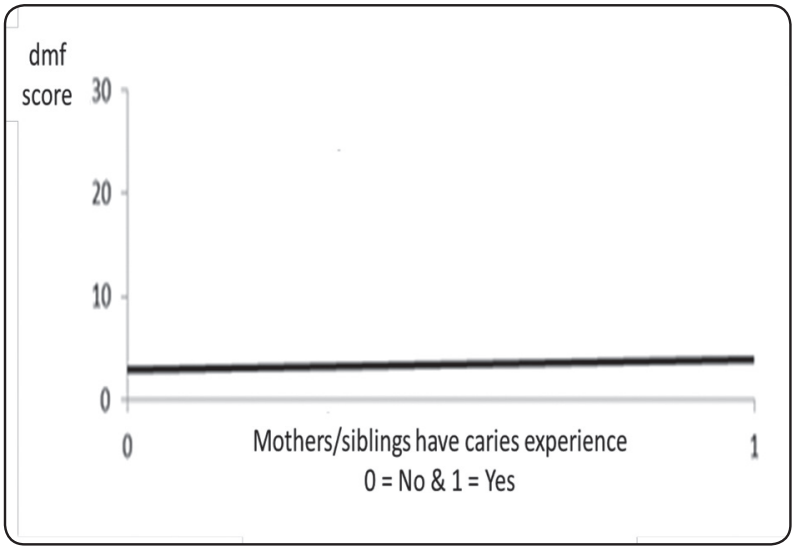

Fig. (5) Correlation betweenMother/siblings caries experience and dmf scores

\section{DISCUSSION}

Though oral health is strongly linked to general health and it is well known that dental caries which is the most common chronic disease in childhood, comprises a costly burden to health services ${ }^{[18]}$ yet in the African and Middle East region countries including Egypt, there is generally scarcity in reliable data on profile of different oral diseases. ${ }^{[19]}$ Based on Egypt's 2013- 2014 national oral health survey from which data of the current study was extracted, $69.2 \%$ of the examined preschool children had a dmf score greater than zero. The high mean score for decayed (d) primary teeth (3.1) and the very low mean score 
for filled teeth (f) which was 0.1 indicate high rates of unmet dental treatment needs for this population group. Similarly at provincial level, in one study in El-Suez governorate, only 113 children (25\%) out of 442 were caries-free ${ }^{[20]}$ and in another study, in Mansoura city, the capital of Dakahlia governorate, in a sample of 1000 children aged 3 to 6 years the prevalence of ECC was found to be $61.4 \%$ and the mean dmft was as high as $2.93 \pm 3.28 .{ }^{[21]}$

According to Abid et al, generally, in low- and middle income countries, health authorities do not consider oral health a priority area and minimal resources are allocated to oral care including oral health promotion and community-based preventive programs. ${ }^{[19]}$ This might explain the high caries trends among Egyptian preschool children. Moreover, because parents are their children's decision makers, their level of knoweldge and attitudes directly affect children's overall health status. ${ }^{[22]}$ As a result, owing to parental poor knowledge of importance of primary teeth for children's growth and development and because of the widespread cultural beliefs that those teeth are temporary and would be replaced by permanent teeth in the long run, ${ }^{[23-25]}$ many parents might fail to seek appropriate dental care for their children. ${ }^{[26]}$

Globally, there are rural-urban variations in terms of access to oral care including preventive and health promotion services in addition to disparities in rates of prevalence of ECC and feeding habits in children. ${ }^{[27,28]}$ In rural areas, even in developed countries, utilization of oral health care services is not usually a common practice either due to shortage of dental practitioners, lack of transportation or financial constraints. ${ }^{[29]}$ Furthermore, generally, people living in urban communities tend to have higher levels of oral health literacy and exhibit more positive oral health-related attitudes than those in rural areas owing to easier access to health information through media among those populations. ${ }^{[27]}$ This might explain the higher percentage of untreated carious lesions among this young age group of Egyptian children residing in rural areas in comparison to their urban counterparts, as indicated by the findings of the current study.

It is also worth mentioning that according to data extracted from Egypt's national oral health survey, Egyptian boys were more liable to suffer from ECC than girls and this goes in line with the findings of another cross sectional study conducted in Cairo governorate. ${ }^{[30]}$ In addition, similar gender disparities in caries experience have been observed in other populations and among both children and adults. ${ }^{[31]}$ A plausible explanation is that usually girls are more inclined to comply with instructions including health messages and in one study it was found that, when instructed, they brushed their teeth more frequently than boys. ${ }^{[32]}$

Regarding the association between other determinants and prevalence of ECC, it was found that though tooth brushing was a protective factor yet the effects were not significant. This might be attributed to inadequate tooth brushing either due to lack of parents' awareness of importance of their active engagement in brushing their children's teeth in this age group or their failure to manage their children's uncooperative behavior who might be resistant and unwilling to open their mouths while brushing their teeth ${ }^{[33]}$

On the other hand, there was a weak to moderate positive association between caries experience and consumption of some sugar-containing snacks and sweets. Though, this has been well-elaborated in many studies on the relationship between various risk determinants and development of ECC. ${ }^{[34-36]}$ yet, it is likely that due to presence of some protective factors such as fluoride exposure the relationship between sugar consumption and dental caries was not strong. ${ }^{[37]}$

Over decades, in various studies, it has been postulated that a moderate to strong association 
exists between maternal caries experience and their children's risk to develop ECC. ${ }^{[38-40]}$. In the current study, though there was a positive coorelation between maternal-child caries experience yet it was found to be weak. However, it is worth mentioning that in our survey, we did not conduct a thorough clinical oral examination for mothers of the enrolled children, instead their previous caries experience was determined based on a Yes/No question in the study tool and this might explain the difference in the level of the association.

One strength of the current study is that data collection followed standardized well-defined criteria from the WHO, which has been used for decades for conducting epidemiological oral health surveys and for promoting comparisons over time at national and international levels. ${ }^{[41]}$ Moreover, the included sample was quite diverse and included different levels of socioeconomic status being selected from various gathering points scattered throughout the country.The sample, also, provided information on caries experience of an age group of children which are not usually part of national oral health surveys.

On the other hand, one limitation is that the sample size might not be large enough, however it is worth mentioning that in the national survey the total sample was divided into two groups according to age; below and above 18 years old based on the population census in January 2013 from Center Agency for Public Mobilization \& Statistics and $60.8 \%$ of the sample was above 18 years old.This might explain why the sample of children in the selected age group (3-6years) was relatively small.

In conclusion, the findings of this study point out that oral health of preschool children might be a neglected health issue in Egypt and this implies that community-based preventive programs targeting expectant mothers during pregnancy and later in early childhood are imperatively needed.

\section{REFERENCES}

1. Moynihan PJ, Kelly SA. Effect on caries of restricting sugars intake: systematic review to inform WHO guidelines. 2014; J Dent Res 93(1):8-18.

2. O’Mullane DM, Baez RJ, Jones S, Lennon MA, Petersen PE, Rugg-Gunn AJ et al. (2016). Fluoride and oral health. Community Dent Health 33(2):69-99.

3. GBD 2015 Disease and Injury Incidence and Prevalence Collaborators. Global, regional, and national incidence, prevalence, and years lived with disability for 310 diseases and injuries, 1990-2015: a systematic analysis for the Global Burden of Disease Study 2015. Lancet. 2016 Oct 8;388(10053):1545-1602.

4. American Academy of Pediatric Dentistry. Definition of early Childhood Caries (ECC). Adopted 2003, Revised 2007, 2008. http://www.aapd.org/assets/1/7/d_ecc.pdf

5. Kim Seow W. Environmental, maternal, and child factors which contribute to early childhood caries: a unifying conceptual model. Int J Paediatr Dent. 2012 May;22(3):157-68.

6. Ferraz NK, Nogueira LC, Pinheiro ML, Marques LS, Ramos-Jorge ML, Ramos-Jorge J. Clinical consequences of untreated dental caries and toothache in preschool children. Pediatr. Dent. 2014 Sep-Oct;36(5):389-92.

7. Fernandes IB, Pereira TS, Souza DS, Ramos-Jorge J, Marques LS, Ramos-Jorge ML. Severity of Dental Caries and Quality of Life for Toddlers and their Families. Pediatr. Dent. 2017 Mar 15;39(2):118-123.

8. Corrêa-Faria P, Daher A, Freire MDCM, de Abreu MHNG, Bönecker M, Costa LR. Impact of untreated dental caries severity on the quality of life of preschool children and their families: a cross-sectional study. Qual Life Res. 2018 Dec; 27(12):3191-3198.

9. Gradella C M, Bernabe E, Bönecker M, Oliveira L B. Caries prevalence and severity, and quality of life in Brazilian 2-to 4-year-old children. Community Dent Oral Epidemiol. 2011; 39: 498-504.

10. American Academy of Pediatric Dentistry. Policy on early childhood caries (ECC): classifications, consequences, and preventive strategies. Pediatr Dent. 2016; 38:52-4.

11. Al-Bluwi GS.Epidemiology of dental caries in children in the United Arab Emirates. Int. Dent. J 2014; 64: 219-228.

12. Kowash MB. Severity of early childhood caries in preschool children attending Al-Ain Dental Centre, United Arab Emirates. Eur Arch Paediatr Dent. 2015Aug;16(4):319-24. 
13. Alkhtib A, Ghanim A, Temple-Smith M, Messer LB, Pirotta M, Morgan M. Prevalence of early childhood caries and enamel defects in four and five-year old Qatari preschool children. BMC Oral Health. 2016 Aug 18;16(1):73.

14. Alhabdan YA, Albeshr AG, Yenugadhati N, Jradi H. Prevalence of dental caries and associated factors among primary school children: a population-based cross-sectional study in Riyadh, Saudi Arabia. Environ Health Prev. Med. 2018 Nov 30;23(1):60.

15. Farooqi FA, Khabeer A, Moheet IA, Khan SQ, Farooq I, ArRejaie AS. Prevalence of dental caries in primary and permanent teeth and its relation with tooth brushing habits among schoolchildren in Eastern Saudi Arabia. Saudi Med J. 2015 Jun;36(6):737-42.

16. World Health Organization, Regional office for the Eastern Mediterranean. Egypt releases results of epidemiological study on oral health status.2014. www.emro.who.int/egy/ egypt-events/results-of-epidemiological-study-on-oralhealth-status-released.html

17. Oral health surveys: Basic methods. Geneva, Switzerland: WHO; 1997. World Health Organization.

18. Casamassimo PS, Thikkurissy S, Edelstein BL, Maiorini E. Beyond the dmft:The human and economic cost of early childhood caries. J Am Dent Assoc. 2009;140:650-7.

19. Abid A, Maatouk F, Berrezouga L, Azodo C, Uti O, ElShamy H, Oginni A. Prevalence and Severity of Oral Diseases in the Africa and Middle East Region. Adv Dent Res. 2015 Jul;27(1):10-7.

20. Farag SM, Rashed MA and Fouad WA. Oral Health status of Preschool children in El Suez Governorate and the influence of Oral health education program. Egyptian Dental journal. 2014; 60: 1103-1113.

21. Shalan HM, Abo Bakr RM. Oral Health Status of Preschool Children in Egypt. Acta Scientific Dental Sciences. 2018;2(5).

22. Nagaveni NB, Radhika NB, Umashankar KV. Knowledge, attitude and practices of parents regarding primary teeth care of their children in Davangere city, India. Pesq Bras Odontoped Clin Integr, João Pessoa 2011 Jan;11(1):129132 .

23. Ng MW. Multicultural influences on child-rearing practices: implications for today's pediatric dentist. Pediatr Dent 2003;25(1):19-22.
24. Riedy CA, Weinstein P, Milgrom P. An ethnographic study for understanding children's oral health in a multi-cultural community. Int Dent J 2001 Aug; 51(4):305-312.

25. Vittoba Setty J, Srinivasan I. Knowledge and Awareness of Primary Teeth and Their Importance among Parents in Bengaluru City, India. Int J Clin Pediatr Dent. 2016;9(1):56-61.

26. PK Domoto. American Academy of Pediatric Dentistry. Dental Neglect in Children. www.aapd.org/assets/1/25/ Loochtan-08-S1.pdf

27. Bayne A, Knudson A, Garg A, Kassahun M. 2013. Promising practices to improve access to oral health care in rural communities. Rural Evaluation Brief, Rural Health Research Center, University of Minnesota. February 2013. Series No.7. http://www.norc.org/PDFs/Walsh\%20Center/Oral_Rural\%20Evaluation\%20Issue\%20Brief-6pg_ mm.pdf

28. Ogunbodede EO, Kida IA, Madjapa HS, Amedari M, Ehizele A, Mutave R, Sodipo B, Temilola S, Okoye L.Oral Health Inequalities between Rural and Urban Populations of the African and Middle East Region. Adv Dent Res. $2015 \mathrm{Jul} ; 27(1): 18-25$.

29. Mariño RJ, Khan AR, Tham R, Khew CW, Stevenson C. Pattern and factors associated with utilization of dental services among older adults in rural Victoria. Aust Dent J. 2014 Dec;59(4):504-10.

30. Kabil NS, Eltawil S. Prioritizing the Risk Factors of Severe Early Childhood Caries. Dent J (Basel). 2017;6;5(1).

31. Shaffer JR, Leslie EJ, Feingold E, Govil M, McNeil DW, Crout RJ, Weyant RJ, Marazita ML.Caries Experience Differs between Females and Males across Age Groups in Northern Appalachia. Int J Dent. 2015.

32. Ashkenazi M1, Cohen R, Levin L. Self-Reported Compliance with Preventive Measures Among Regularly Attending Pediatric Patients. J Dent Educ. 2007;71(2):287-95.

33. Marshman Z, Ahern SM, McEachan RRC, Rogers HJ, Gray-Burrows KA4, Day PF. Parents' Experiences of Toothbrushing with Children : A Qualitative Study. JDR Clin Trans Res. 2016 Jul; 1(2): 122-130.

34. Wulaerhan J, Abudureyimu A, Bao XL, Zhao J. Risk determinants associated with early childhood caries in Uygur children: a preschool-based cross-sectional study. BMC Oral Health. 2014;14:136. 
35. Sun HB, Zhang W, Zhou XB. Risk Factors associated with Early Childhood Caries. Chin J Dent Res. 2017;20(2): 97-104.

36. American Academy of Pediatric Dentistry. Policy on Dietary Recommendations for Infants, Children, and Adolescents. Revised 2017. http://www.aapd.org/media/Policies_Guidelines/P_RecDietary.pdf

37. Burt BA, Satishchandra P. The relationship between low birthweight and subsequent development of caries: A systematic review. J Dent. Edu. 2001;65(10):1017-23.

38. Costa EL, Costa JF, Santos MP, Ladeira LLC, Silva RA, Ribeiro CCC. Streptococcus mutans in Mother-Child Dyads and Early Childhood Caries: Examining Factors
Underlying Bacterial Colonization. Caries Res. 2017 Oct 21;51(6):582-589.

39. Dye BA, Vargas CM, Lee JJ, Magder L, Tinanoff N. Assessing the relationship between children's oral health status and that of their mothers. JADA; 2011; 142: 173-83.

40. Chaffee BW, Gansky SA, Weintraub JA, Featherstone JDB, Ramos-Gomez FJ. Maternal Oral Bacterial Levels Predict Early Childhood Caries Development. Journal of Dental Research; 2014; 93: 238-44.

41. Petersen PE, Bourgeois D, Bratthall D, Ogawa H. Oral health information systems-towards measuring progress in oral health promotion and disease prevention. Bull World Health Org. 2005;83:686-93. 